\title{
Understanding and modelling the economic impact of spinal cord injuries in the United Kingdom
}

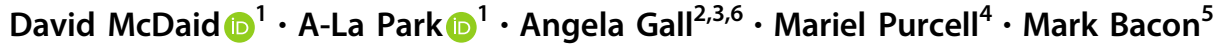

Received: 27 September 2018 / Revised: 22 April 2019 / Accepted: 23 April 2019 / Published online: 13 May 2019

(c) The Author(s) 2019. This article is published with open access

\begin{abstract}
Study design Economic modelling analysis.

Objectives To determine lifetime direct and indirect costs from initial hospitalisation of all expected new traumatic and nontraumatic spinal cord injuries (SCI) over 12 months.

Setting United Kingdom (UK).

Methods Incidence-based approach to assessing costs from a societal perspective, including immediate and ongoing health, rehabilitation and long-term care directly attributable to SCI, as well as aids and adaptations, unpaid informal care and participation in employment. The model accounts for differences in injury severity, gender, age at onset and life expectancy. Results Lifetime costs for an expected 1270 new cases of SCI per annum conservatively estimated as $£ 1.43$ billion (2016 prices). This equates to a mean $£ 1.12$ million (median $£ 0.72$ million) per SCI case, ranging from $£ 0.47$ million (median $£ 0.40$ million) for an AIS grade D injury to $£ 1.87$ million (median $£ 1.95$ million) for tetraplegia AIS A-C grade injuries. Seventy-one percent of lifetime costs potentially are paid by the public purse with remaining costs due to reduced employment and carer time.

Conclusions Despite the magnitude of costs, and being comparable with international estimates, this first analysis of SCI costs in the UK is likely to be conservative. Findings are particularly sensitive to the level and costs of long-term home and residential care. The analysis demonstrates how modelling can be used to highlight economic impacts of SCI rapidly to policymakers, illustrate how changes in future patterns of injury influence costs and help inform future economic evaluations of actions to prevent and/or reduce the impact of SCIs.
\end{abstract}

David McDaid

d.mcdaid@1se.ac.uk

1 Personal Social Services Research Unit, Department of Health Policy, London School of Economics and Political Science, London, UK

2 London Spinal Cord Injury Centre, Royal National Orthopaedic Hospital, Stanmore, UK

3 University College London, London, UK

4 Queen Elizabeth National Spinal Injuries Unit, Queen Elizabeth University Hospital, Glasgow, UK

5 Spinal Research, London, UK

6 Present address: Department of Rehabilitation Medicine, Woodend Hospital, Aberdeen and University of Aberdeen, Aberdeen, UK

\section{Introduction}

The United Kingdom (UK) experiences around 16 new cases per million population in traumatic spinal cord injuries $[1,2]$ and $2-3$ new cases per million population in nontraumatic spinal cord injuries per annum [1]. This is $>1200$ new spinal cord injuries (SCIs) every year, the majority due to traumatic events, with the remainder resulting from disease, such as non-malignant tumours.

These SCIs can have devastating, life-changing impacts on those injured and their families. Economic evaluation can help make the case for investing in actions to reduce these injuries, as well as better manage and support people living with SCI. It can help determine the incremental costeffectiveness of actions compared to usual care.

A pre-requisite for any economic evaluation is to quantify the economic costs of SCI to different sectors/stakeholders. These include National Health Service (NHS) costs for immediate and ongoing healthcare use, not only in 
dealing with SCI and its many chronic complications, including pressure sores, respiratory, cardiovascular and urinary/bowel problems [3], but also treating higher risks of multi-morbidity, such as depression and obesity [4]. Social care services, the NHS and people with SCI will also share rehabilitation, residential and home care costs, including aids and modifications. Public employment and education services will fund reintegration into work or school. Indirect costs borne by society typically relate to lost employment and the need for family members to give up their time to provide informal care.

Despite the importance of economic evidence in health policymaking in the UK and many countries, there are surprisingly few estimates of SCI costs. While UK studies on the cost-effectiveness of interventions for SCI and complications have been published [5], no detailed estimates of overall costs of SCI to the healthcare system, wider public purse and society in a UK context exist. Indeed, National Institute for Health and Care Excellence (NICE) guidelines relied on an expert opinion estimate of $£ 2.5$ million in lifetime costs for spinal injury, with values ranging from $£ 0$ to $£ 10$ million [2]. Given this lack of information, we aimed to model lifetime costs of SCI in the UK. This will also have broader value, as the model could be adapted to other country contexts.

\section{Methods}

A Microsoft-Excel simulation model estimated net present value lifetime costs for all new hospital presenting cases of SCIs in the UK in 1 year. This incidence-based costing approach is powerful as it allows subsequent economic evaluations to illustrate potentially avoidable long-term costs if interventions are effective in preventing and/or reducing the impacts of any health problem [6]. It has been used to estimate lifetime costs of SCIs in Australia, Canada and the US [7-11]. Figure 1 provides an overview of model structure following presentation to hospital for SCIs. If individuals survive hospitalisation, including rehabilitation, they are either discharged home or to residential care. Costs are incurred over remaining lifespans. The economic analysis includes immediate and ongoing healthcare costs directly attributable to SCIs, as well as costs of aids, adaptations, home modifications and provision of homebased and residential care. Unpaid informal care costs and reduced rates of participation in employment are also included.

All costs are in 2016 UK pounds, where necessary using the International Monetary Fund's World Economic Outlook Purchasing Power Parity 2016 implied inflation and conversion factors. Costs beyond 1 year are discounted at the UK HM Treasury Green Book recommended rate of $3.5 \%$ per annum.

\section{Incidence data}

Given the absence of a single source of UK-wide incidence data, the model used data from the Queen Elizabeth National Spinal Injuries Unit (QENSIU). QENSIU (https://www.spinalunit.scot.nhs.uk/) has treated all new cases of traumatic SCI in patients aged $>12$ years in Scotland for $>20$ years [1]. Mean annual incidence rates for traumatic and non-traumatic paraplegic and tetraplegic SCIs broken down by gender and 10-year age groups for the period 2009-2013 were available [1].

In QENSIU, neurological level of injury was assessed by a spinal injury consultant on admission and defined according to the International Neurological Classification of Spinal Injury using the American Spinal Injury Association Impairment Scale (AIS). This economic analysis uses this data to group traumatic injuries at admission between more severe AIS-ABC grades for both paraplegia and tetraplegia and all AIS-D grade injuries. Conservatively, it assumes that all reported non-traumatic injuries are AIS-D grade even though at least a third of these injuries could be more severe and costly [12]. UK Office of National Statistics mid-year age- and gender-specific population age estimates for the four UK nations in 2016 were used to calculate the number of new SCIs nationwide.

Many different approaches have been used to estimate short- and long-term impacts on mortality of SCIs [13]. Here costs were adjusted to account for 1-year post-injury mortality rates for paraplegic/tetraplegic AIS-ABC or all $\mathrm{D}$ grades [14]. The model accounts for longer-term survival by age group, gender and injury severity using a 70year study of life expectancy for patients at two English SCI centres [15].

\section{Resource use and unit costs}

Table 1 provides resource use, unit costs and other parameters used in the model. Where possible, we made use of UK sources but otherwise drew on international literature. We used HRG (Healthcare Resource Groups) tariffs for costs of immediate hospital episodes for SCI in the 2015-2016 English National Schedule of Reference Costs [16]. As England represented $84 \%$ of the UK population, we applied these costs UK wide, even though they are only used for reimbursement in England. This approach is conservative as some costs in specialist SCI centres may be higher than these tariffs. Tariffs do not directly distinguish between traumatic and non-traumatic injuries; we assume all traumatic SCI events involve an immediate non-elective hospital stay, plus costs for ambulatory 


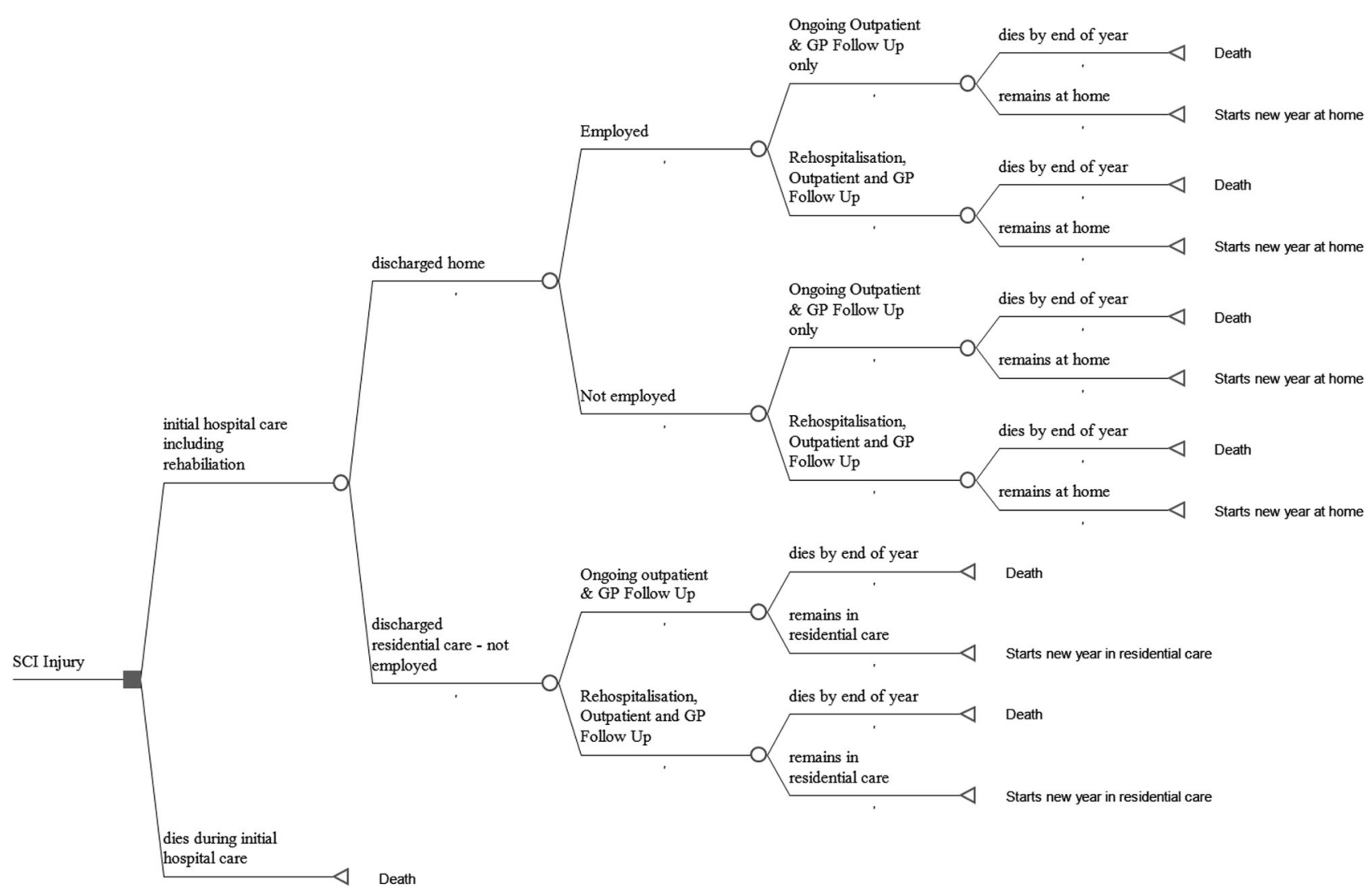

Fig. 1 Overview of model structure

transport/treatment. Non-traumatic SCIs conservatively are assumed to involve an episode of elective hospital treatment. Costs of excess bed days beyond the maximum permitted using these tariff codes have been included. We assumed tetraplegic injuries involve the HC21D tariff for the higher level of complications and comorbidities (CC) Score 2+: maximum length of stay of 123 days, beyond which additional payments are made. Conservatively all AIS-D grade injuries are valued using a short-stay tariff used for patients with length of stay of 2 days maximum.

Rates of rehospitalisation for discharged rehabilitation patients with SCI can be high, in excess of $50 \%$ of patients with more severe trauma may be readmitted at least once within 1 year [17-19]. Common reasons for rehospitalisation include respiratory and urinary tract infections, as well as fractures; this typically occurs in a local hospital rather than specialist SCI centre. Specialist centres deal with highly specialist issues, e.g. pressure sore management, complex rehabilitation needs or spine surgery. Annual readmission rates to any hospital following postrehabilitation discharge and the number of rehospitalisations were based on US analysis for specialist rehabilitation centres, again distinguishing between rates for tetraplegia and paraplegia $\mathrm{ABC}$ grades as well as all $\mathrm{D}$ grade injuries
[19]. We have very conservatively used short length of stay tariffs for all readmissions, even though some stays will be reimbursed using full tariffs used for initial admissions for $\mathrm{ABC}$ grade injuries. All outpatient consultations were valued using a non-mandatory English tariff for consultantled SCI follow-up consultations, assuming a mean of 1.79 outpatient consultations per annum observed in Denmark [17]. We also drew on this Danish analysis to estimate 9.94 GP consultations per annum related to SCI.

The need for home/vehicle modifications depends on injury severity. A Swiss survey of 482 people with SCI reported $85 \%$ had at least one home adaptation [20], most commonly a wheelchair-accessible shower (63\%). Published estimates of adaptation costs vary considerably; we use estimates from Australian analysis of SCI costs. This included mean costs for home/transport adaptations, ventilation equipment, special beds and communication aids, as well as vocational equipment, education and training courses [7]. To be conservative, we only applied these costs to the $\mathrm{ABC}$ grades of tetraplegia and paraplegia.

The model also accounts for immediate/ongoing costs following discharge to specialist residential care. This is conservative as the increased likelihood of subsequent transfer to residential care after 1 year is not included. Although it is suggested that $20 \%$ of UK SCI patients could 
Table 1 Parameters used in model

\begin{tabular}{|c|c|c|c|}
\hline Description of model parameter & Value & Unit & Source \\
\hline Non-elective spinal cord injury with CC Score 2+ (HC21D) & $£ 20,448.28$ & Episode (including excess days) & {$[16]$} \\
\hline Elective spinal cord injury with CC Score $2+$ (HC21D) & $£ 10,034.00$ & Episode (including excess days) & {$[16]$} \\
\hline Non-elective spinal cord injury with CC Score $0-1$ (HC21E) & $£ 6741.14$ & Episode (including excess days) & {$[16]$} \\
\hline Elective spinal cord injury with CC score $0-1$ (HC21E) & $£ 4305.00$ & Episode (including excess days) & {$[16]$} \\
\hline $\begin{array}{l}\text { Non-elective spinal cord injury with CC Score } 2+\text { (short stay) } \\
\text { (HC21D) }\end{array}$ & $£ 2200.98$ & Episode & {$[16]$} \\
\hline $\begin{array}{l}\text { Non-elective spinal cord injury with CC Score } 0-1 \text { (short stay) } \\
\text { (HC21E) }\end{array}$ & $£ 963.17$ & Episode & {$[16]$} \\
\hline Ambulance see, treat and convey (ASS02) & $£ 236$ & Per contact & {$[16]$} \\
\hline Non-admitted, face to face consultant led follow- up (WF01A) & $£ 289$ & Per consultation & {$[16]$} \\
\hline GP consultation & $£ 45$ & Per consultation & {$[26]$} \\
\hline Tetraplegia ABC year 1 modifications/adaptations & $£ 6781$ & Per person per annum & [7] \\
\hline Tetraplegia ABC year 2 modifications/adaptations & $£ 27,144$ & Per person per annum & {$[7]$} \\
\hline Tetraplegia ABC year 3 modifications/adaptations & $£ 11,935$ & Per person per annum & [7] \\
\hline Tetraplegia ABC year 4 modifications/adaptations & $£ 6078$ & Per person per annum & [7] \\
\hline Tetraplegia ABC year 5 modifications/adaptations & $£ 5876$ & Per person per annum & [7] \\
\hline Tetraplegia ABC year 6 modifications/adaptations & $£ 6527$ & Per person per annum & [7] \\
\hline Tetraplegia $\mathrm{ABC}$ year $7+$ modifications/adaptations & $£ 3263$ & Per person per annum & [7] \\
\hline Paraplegia ABC year 1 modifications/adaptations & $£ 5878$ & Per person per annum & [7] \\
\hline Paraplegia ABC year 2 modifications/adaptations & $£ 17,178$ & Per person per annum & [7] \\
\hline Paraplegia ABC year 3 modifications/adaptations & $£ 16,628$ & Per person per annum & {$[7]$} \\
\hline Paraplegia ABC year 4 modifications/adaptations & $£ 8578$ & Per person per annum & [7] \\
\hline Paraplegia ABC year 5 modifications/adaptations & $£ 8045$ & Per person per annum & [7] \\
\hline Paraplegia ABC year 6 modifications/adaptations & $£ 5844$ & Per person per annum & {$[7]$} \\
\hline Paraplegia $\mathrm{ABC}$ year $7+$ modifications/adaptations & $£ 2922$ & Per person per annum & [7] \\
\hline Tetraplegia $\mathrm{ABC}$ rehospitalisation rates in 12 months & 44.9 & $\%$ & {$[19]$} \\
\hline Intermediate specialist nursing home care & $£ 1294$ & Per week & {$[23]$} \\
\hline High specialist nursing home care & $£ 1656$ & Per week & {$[23]$} \\
\hline Very high specialist nursing home care & $£ 2277$ & Per week & {$[23]$} \\
\hline Tetraplegia $\mathrm{ABC}$ rehospitalisation rates in 12 months & 44.9 & $\%$ & {$[19]$} \\
\hline Paraplegia $\mathrm{ABC}$ rehospitalisation rates in 12 months & 35.3 & $\%$ & [19] \\
\hline All $\mathrm{D}$ grades rehospitalisation rates in 12 months & 23.8 & $\%$ & [19] \\
\hline $\begin{array}{l}\text { Tetraplegia } \mathrm{ABC} \text { average number of rehospitalisations in } \\
12 \text { months }\end{array}$ & 1.45 & Mean rehospitalisations & {$[19]$} \\
\hline $\begin{array}{l}\text { Paraplegia } \mathrm{ABC} \text { average number of rehospitalisations in } \\
12 \text { months }\end{array}$ & 1.28 & Mean rehospitalisations & [19] \\
\hline All $\mathrm{D}$ average number of rehospitalisations in 12 months & 1.33 & Mean rehospitalisations & [19] \\
\hline Mean number of outpatient consultations per annum & 1.79 & Mean outpatient consultation per person & {$[17]$} \\
\hline Mean GP consultations per annum & 9.94 & Mean GP consultations per person & {$[17]$} \\
\hline $\begin{array}{l}\text { Discharge rate to nursing homes in } 1 \text { year postinjury for all SCI } \\
\text { injuries }\end{array}$ & 6 & $\%$ & {$[22]$} \\
\hline Paraplegia $\mathrm{ABC}$ mean hours of professional home care & 30.9 & Mean hours per week & {$[25]$} \\
\hline Tetraplegia $\mathrm{ABC}$ mean hours of professional home care & 58.1 & Mean hours per week & {$[25]$} \\
\hline All D mean number of hours of professional home care & 5 & Mean hours per week & Authors' assumption \\
\hline Paraplegia ABC mean hours of family home care & 16.03 & Mean hours per week & [7] \\
\hline Tetraplegia $\mathrm{ABC}$ mean hours of family home care & 28.0 & Mean hours per week & [7] \\
\hline All D mean hours of family home care & 4.9 & Mean hours per week & {$[24]$} \\
\hline Home care (local authority provided) & $£ 30.75$ & Rate per hour & {$[26]$} \\
\hline
\end{tabular}


Table 1 (continued)

\begin{tabular}{|c|c|c|c|}
\hline Description of model parameter & Value & Unit & Source \\
\hline Employment rate for paraplegia $\mathrm{ABC}$ & 40.2 & $\%$ & {$[28]$} \\
\hline Employment rate for tetraplegia $\mathrm{ABC}$ & 31.4 & $\%$ & {$[29]$} \\
\hline Employment rate for all D injuries & 71.0 & $\%$ & {$[31]$} \\
\hline $\begin{array}{l}\text { General employment rate in population without disability } \\
\text { in the UK }\end{array}$ & 79.0 & $\%$ & [29] \\
\hline Minimum wage over $25 \mathrm{~s}$ & $£ 7.20$ & Per hour & {$[27]$} \\
\hline Annual wage 16 and 17 year olds & $£ 6386$ & Per annum & {$[27]$} \\
\hline Median annual wage $18-21$ & $\begin{array}{l}\text { M: } £ 11,283 \\
\text { W: } £ 7695\end{array}$ & Per annum & {$[32]$} \\
\hline Median annual wage $22-29$ & $\begin{array}{l}\text { M: } £ 22,221 \\
\text { W: } £ 17,796\end{array}$ & Per annum & {$[32]$} \\
\hline Median annual wage $30-39$ & $\begin{array}{l}\text { M: } £ 29,799 \\
\text { W: } £ 20,488\end{array}$ & Per annum & {$[32]$} \\
\hline Median annual wage $40-49$ & $\begin{array}{l}\text { M: } £ 33,207 \\
\text { W: } £ 19,319\end{array}$ & Per annum & {$[32]$} \\
\hline Median annual wage 50-59 & $\begin{array}{l}\text { M: } £ 31,842 \\
\text { W: } £ 18,572\end{array}$ & Per annum & {$[32]$} \\
\hline Median annual wage $60-67$ & $\begin{array}{l}\text { M: } £ 23,929 \\
\text { W: } £ 12,832\end{array}$ & Per annum & {$[32]$} \\
\hline
\end{tabular}

$C C$ complications and comorbidities, $G P$ general practitioner

be discharged to residential care [21], we use a more conservative estimate of $6 \%$ reported in discharge data from specialist SCI centres [22]. UK costs for specialist intermediate, high and very high levels of nursing home care are applied to grade $\mathrm{D}$, paraplegia $\mathrm{ABC}$ and tetraplegia $\mathrm{ABC}$ grades, respectively [23]. In the year postinjury, these costs are adjusted given time already spent in hospital to avoid double counting. Unit costs used are at the low end of reported cost ranges; individuals with more complex needs, e.g. on ventilators, are likely to incur substantially higher costs than used in the model. The model also does not account for higher background risk of residential care admission for older people regardless of SCI status.

The analysis includes costs of long-term home-based attendant/nursing care. This varies depending on care needs, from 24-h 7-day-a-week care to little or no care. An evaluation of specialist neuro-rehabilitation in the north of England simply estimated costs for 168 and $14 \mathrm{~h}$ per week care due to lack of data [5]. We identified analysis where 48 patients 1 year after discharge from a specialist SCI centre in England received a mean $80 \mathrm{~h}$ of paid care per week, (range 1-168 h) [24]. In all, 63\% were classified as having paraplegia or tetraplegia AIS grades $\mathrm{ABC}$ with the remainder AIS-D grades at 1 year follow-up.

The model assumes on average individuals with paraplegia or tetraplegia $\mathrm{ABC}$ grades living at home receive 30.87 and $58.1 \mathrm{~h}$ of paid care per week, respectively. This is more conservative than the 80 -h per week estimate in the English analysis we identified. These values are based on a breakdown of care use in the United States [25] that we have reduced to take account of expected informal care received; for all AIS-D grade injuries, we conservatively assume a mean of $5 \mathrm{~h}$ of contact per week based on our own expert experience of SCI patients in Scotland. All hours are costed using hourly rates for local authority provided home care in England in 2016 [26].

Few estimates of informal family care provided to people with SCI have been published. We were unable to find UK costs, so we used estimates from Australia on informal care received by individuals with tetraplegia and paraplegia [7]. There is almost no information on informal care for AIS-D grade injuries; the model assumed a mean of $1 \mathrm{~h}$ per day based on a small English analysis [24]. As in the Australian analysis, the model assumed only $70 \%$ of SCI cases would have access to informal care. Costs were valued using the hourly national minimum wage for the over 25s [27].

Employment rates came from an English survey of 1700 working age people who had used specialist SCI centre care; only $40.2 \%$ of paraplegia $\mathrm{ABC}$ injuries and $31.4 \%$ of tetraplegia $\mathrm{ABC}$ injuries were employed [28]. This contrasts with a $79 \%$ employment rate for 'all working age people who are not classified disabled and/or work-limiting disabled' [29]. Pain, fatigue and older age are among reasons for reduced employment for AIS-Ds, but data on actual employment rates is sparse [30]. We assumed $71 \%$ of those of working age would be in employment, using Canadian analysis [31]. Median annual pay rates from the UK Annual Survey of Hours and Earnings are used to 
value productivity losses for individuals aged 18-67 years [32], with minimum wage rate used for losses in 16-17year olds [27]. This is conservative; individuals aged $<16$ years will lose educational opportunities, while some aged $>67$ years might have remained in the labour market or otherwise contributed to the economy, such as by volunteering or providing care.

\section{Results}

The model estimates 1270 (913 male, 357 female) new SCI cases per annum, of which $13 \%$ would be non-traumatic. Table 2 indicates approximately $35 \%$ of SCIs would be tetraplegia $\mathrm{ABC}$ injuries and $18 \%$ paraplegia $\mathrm{ABC}$ injuries. Nearly $70 \%$ of SCIs are for individuals aged $>46$ years. Overall estimated lifetime costs for new cases of SCI are $£ 1.43$ billion (Table 3 ). More than $£ 60$ million of costs are for the first year of care, with $50 \%$ of costs incurred by those aged $>56$ years (Table 4 ). In all, $71 \%$ of lifetime costs potentially fall on the public purse and $29 \%$ of costs are due to reduced employment of people living with SCI, as well family carer time.

Fifty-one million pounds in specialist hospital-based healthcare service costs is likely to be conservative; these are greatest for tetraplegia $\mathrm{ABC}$ cases, accounting for $>2.9 \%$ of their lifetime costs. This figure does not include further substantive costs in hospital/home for the most complex cases of SCI, including ventilation. Anecdotally, we are aware of annual costs in excess of $£ 320,000$ per annum for 24/7 home care for a person with SCI requiring ventilation.

Figure 2 illustrates mean expected lifetime costs per SCI case. Overall, costs would be $£ 1.12$ million per SCI, ranging from $£ 0.47$ million per person with grade $\mathrm{D}$ injuries to $£ 1.87$ million per tetraplegia $\mathrm{ABC}$ injury. Mean lifetime costs per woman are higher: $£ 1.15$ million versus $£ 1.11$ million per man. Median lifetime costs per SCI of $£ 0.72$ million are lower reflecting the concentration of injuries in older age groups. Median costs range from $£ 0.40$ million per grade $D$ injury to $£ 1.95$ million per tetraplegia $\mathrm{ABC}$ injury. Median lifetime costs per woman are higher: $£ 0.80$ million versus $£ 0.72$ million per man.

\section{Sensitivity analyses}

Sensitivity analyses explored impacts of changing key model assumptions. The maximum initial tariff for nonelective traumatic complex spinal injuries used was $£ 20,448$, with much lower tariffs used for less severe injuries; even with rapid transfer to specialist SCI centres, care costs for some can be much higher, especially if requiring long-term ventilation. A French study reported $6.5 \%$ of new traumatic SCI cases required long-term ventilation [33]. If $6.5 \%$ of all traumatic tetraplegia cases required ventilation, with mean 60-day stay in a specialist centre at $£ 981$ per day [34] their individual costs would increase to $£ 58,860$ and lifetime mean costs for all tetraplegia $\mathrm{ABC}$ grades increase from $£ 1.870$ million to $£ 1.873$ million. Overall costs of SCI would rise marginally to $£ 1.428$ billion from $£ 1.427$ billion. If $20 \%$ of tetraplegia cases required ventilation, costs would rise to $£ 1.431$ billion overall and $£ 1.878$ million per tetraplegia $\mathrm{ABC}$ case. The model thus appears relatively insensitive to increasing immediate healthcare costs associated with the most traumatic cases, although additional costs of complications, such as dealing with pressure sores and infections, are not included. We conservatively used short-stay HRG tariffs for grade $\mathrm{D}$ injuries and rehospitalisations for $\mathrm{ABC}$ grade injuries. The model is more sensitive to changes in this assumption. For each additional $10 \%$ of D injuries and all $\mathrm{ABC}$ rehospitalisations that required a longer stay (qualifying full tariff reimbursement), overall costs increased by $£ 13$ million.

The model is sensitive to professional home care assumptions. If all individuals with tetraplegia $\mathrm{ABC}$ injuries received 7.3 home care hours per day (less informal care time) rather than $12.3 \mathrm{~h}$ per day, then overall costs fall to $£ 1.11$ billion and mean lifetime costs per individual with tetraplegia $\mathrm{ABC}$ injuries to $£ 1.15$ million. If total hours of professional care are not reduced to take account of expected mean informal care received, costs increase to $£ 1.78$ billion. If the $6.5 \%$ of people with tetraplegia $\mathrm{ABC}$ who might require long-term ventilation were also to need 24-hour daily home care, then total lifetime costs would rise to $£ 1.83$ billion, with mean lifetime costs per tetraplegia $\mathrm{ABC}$ case increasing to $£ 2.56$ million.

The home care hourly rate also impacts on care costs. If a lower hourly rate for personal care of $£ 14.28$ [26] is used, then overall costs of SCIs fall to $£ 1.18$ billion. The model is also sensitive to assumptions on use of long-stay residential care. If $20 \%$ (rather than $6 \%$ ) of tetraplegia and paraplegia $\mathrm{ABC}$ cases were discharged from hospital to residential care [21], then overall costs increase to $£ 1.80$ billion, with mean lifetime costs of $£ 2.48$ million and $£ 1.85$ million, respectively.

\section{Discussion}

An incidence-based costing approach provides policymakers with information on long-term impacts; new UK cases of SCI per annum may incur lifetime costs exceeding $£ 1.43$ billion or $£ 1.12$ million per case, with more than two thirds of costs potentially falling on the public purse. 
Table 2 Estimated new cases of SCI in the UK in 2016
Table 3 Lifetime costs of new spinal cord injuries in the UK in 2016 (£s 2016 prices)

\begin{tabular}{llllll}
\hline Age group, years & $\begin{array}{l}\text { Paraplegia- } \\
\text { ABC }\end{array}$ & $\begin{array}{l}\text { Tetraplegia- } \\
\text { ABC }\end{array}$ & All D & Total & $\begin{array}{l}\text { Percentage of } \\
\text { total cases }\end{array}$ \\
\hline $0-15$ & 3 & 6 & 6 & 16 & $1.27 \%$ \\
$16-25$ & 24 & 48 & 59 & 131 & $10.31 \%$ \\
$26-35$ & 22 & 43 & 53 & 118 & $9.30 \%$ \\
$36-45$ & 22 & 43 & 67 & 132 & $10.38 \%$ \\
$46-55$ & 41 & 80 & 116 & 237 & $18.67 \%$ \\
$56-65$ & 40 & 79 & 118 & 237 & $18.63 \%$ \\
$66-75$ & 44 & 86 & 119 & 249 & $19.57 \%$ \\
$76-85$ & 26 & 50 & 58 & 133 & $10.50 \%$ \\
$86+$ & 4 & 7 & 7 & 17 & $1.36 \%$ \\
Total & 225 & 442 & 603 & 1270 & \\
Percentage of total cases & $17.69 \%$ & $34.80 \%$ & $47.51 \%$ & & \\
\hline
\end{tabular}

$S C I$ spinal cord injury

\begin{tabular}{llllll}
\hline All & $\begin{array}{l}\text { Paraplegia } \\
\text { ABC }\end{array}$ & $\begin{array}{l}\text { Tetraplegia } \\
\text { ABC }\end{array}$ & All D & Total cost \\
\hline Immediate inpatient care costs & $1,561,340$ & & & \\
Initial home and vehicle & $1,259,756$ & $2,141,768$ & & $1,085,259$ & $11,788,367$ \\
modifications & & & & & $3,940,665$ \\
Ongoing home modifications & $20,018,649$ & $32,834,814$ & 0 & $52,853,463$ \\
Ongoing healthcare costs & $5,822,627$ & $14,925,680$ & $18,360,452$ & $39,108,759$ \\
Initial home care costs & $4,972,049$ & $17,262,371$ & $2,202,335$ & $24,436,755$ \\
Ongoing home care costs & $179,650,347$ & $511,312,375$ & $93,463,185$ & $784,425,907$ \\
Initial residential care costs & 553,653 & $1,404,319$ & $1,183,112$ & $3,141,083$ \\
Ongoing residential care costs & $20,004,608$ & $41,595,991$ & $50,209,180$ & $111,809,779$ \\
Initial family care costs & 604,532 & $1,947,914$ & 505,355 & $3,057,802$ \\
Ongoing family care costs & $21,843,002$ & $57,697,312$ & $21,467,517$ & $101,007,831$ \\
Productivity losses & $59,912,035$ & $135,729,880$ & $96,014,860$ & $291,656,775$ \\
Total & $316,202,599$ & $826,533,331$ & $284,491,256$ & $1,427,227,187$ \\
\hline
\end{tabular}

This estimate is conservative. For instance, $£ 21.4$ million is spent annually on spinal cord rehabilitation services in England (HRG code VC08Z) [22], but we do not know the proportion for new SCI cases. We have not included additional costs for treatment/management of specific complications or multi-morbidities, including any support from mental health specialists. In Australia, initial hospitalisation costs for those aged $>65$ years who experienced traumatic SCI were $30 \%$ higher (mean difference £3611) than for the under $65 \mathrm{~s}$ due to greater co-morbidities [35]. Nor does it include lifetime costs of essential drug therapies or ventilator dependence. We omit costs associated with delays in reaching specialist SCI units from critical care settings, as well as avoidable delayed discharges from specialist settings due to limited suitable accommodation [34]. We omit adverse impacts on quality of life or social exclusion that substantially increase societal costs. Our estimate of non-traumatic SCI cases is probably conservative, based on attendance at one specialist SCI centre, as some less severe cases may not be referred to these services. We have not captured costs of treatment activity for non-traumatic SCI related to underlying morbidities, such as vascular disorders or malignancies, where these costs are reimbursed under a different HRG tariff. Furthermore, we assumed a high employment rate for AISD cases $(71 \%)$, but little is known on actual employment rates, nor does our model account for return to part-time rather than full-time work.

International studies point to substantive costs but estimates vary greatly and interpretation is difficult due to differences in health/social care systems. Studies use a variety of methodologies, define SCIs in different ways and focus on different elements of cost. Few include nontraumatic SCIs.

Several used incidence-based costing approaches. A model for traumatic SCIs in Australia reported lifetime costs 
of $£ 2.73$ million and $£ 5.2$ million per paraplegia or tetraplegia case, respectively. These costs are higher than our analysis ( $£ 1.41$ million and $£ 1.87$ million, respectively), mainly because the Australian model includes the monetary value for lost quality of life due SCI disability. It estimated that each year of full quality life lost would cost $£ 91,750$ [7]. These costs are not borne by the public purse and the values are open to challenge; in the UK values between $£ 20,000$ and $£ 30,000$ per year of full quality life are typically used [2]. Excluding these costs and looking solely at health, long-term care, aids and adaptations, lifetime costs in the Australian model for paraplegia and tetraplegia were $£ 1.11$ million and $£ 2.77$ million, respectively. Remaining differences are due to Australian inclusion of some costs of

Table 4 Total costs by age group in initial year of SCI in the UK in 2016 (£s 2016 prices)

\begin{tabular}{lllll}
\hline $\begin{array}{l}\text { Age } \\
\text { group, years }\end{array}$ & $\begin{array}{l}\text { Paraplegia } \\
\text { ABC }\end{array}$ & $\begin{array}{l}\text { Tetraplegia } \\
\text {-ABC }\end{array}$ & All D & Total cost \\
\hline $0-15$ & 135,574 & 488,925 & 63,734 & 688,232 \\
$16-25$ & $1,130,947$ & $3,910,368$ & 758,369 & $5,799,684$ \\
$26-35$ & $1,209,899$ & $3,953,977$ & 966,054 & $6,129,930$ \\
$36-45$ & $1,245,033$ & $4,033,442$ & $1,268,831$ & $6,547,306$ \\
$46-55$ & $2,285,565$ & $7,429,094$ & $2,173,540$ & $11,888,199$ \\
$56-65$ & $2,162,988$ & $7,110,349$ & $2,058,266$ & $11,331,603$ \\
$66-75$ & $2,312,026$ & $7,648,383$ & $2,007,549$ & $11,967,958$ \\
$76-85$ & $1,053,393$ & $3,798,898$ & 569,262 & $5,421,553$ \\
$86+$ & 145,624 & 525,169 & 68,459 & 739,251 \\
Total cost & $11,681,047$ & $38,898,605$ & $9,934,063$ & $60,513,715$ \\
\hline
\end{tabular}

SCI spinal cord injury treating multi-morbidities, as well as not accounting for the lower costs of D grade injuries.

A Canadian model estimated lower lifetime costs (including quality-of-life losses valued at $£ 28,841$ per year) between a mean $£ 0.89$ million for incomplete paraplegia to $£ 1.82$ million for complete tetraplegia [8]. This is mainly due to much lower assumed costs for residential care. Another Canadian study reported net lifetime healthcare costs per traumatic SCI case compared to a matched population without SCI. Incremental costs were between $£ 0.14$ million and $£ 0.28$ million, depending on rehabilitation and pre-existence of pressure ulcers [9]. Gross lifetime costs, not deducting non-SCI healthcare costs, were modestly higher, ranging from $£ 0.17$ million to $£ 0.31$ million.

In a US model health, rehabilitation and long-term care mean lifetime costs were between $£ 0.58$ million and $£ 4.20$ million depending on age and injury severity [10]. In another, mean lifetime all-cause hospital costs for thoracic SCI were calculated using data from 14 specialist SCI centres [11]. Costs were $£ 0.23, £ 0.18, £ 0.13$ and $£ 0.05$ million for each AIS grade A-D, respectively. This study did not include health, long-term care or rehabilitation costs outside of hospital.

In our analysis, mean initial year costs per case for hospitalisation, aids and adaptation, as well as any residential or home care use, were $£ 39,846$, 273,393 and $£ 8,246$ for paraplegia $\mathrm{ABC}$, tetraplegia $\mathrm{ABC}$ and AIS-D, respectively. In Australia, mean initial costs of hospitalisation for traumatic SCI, including initial rehabilitation as well as acute care, were estimated as $£ 11,652$ and $£ 15,264$

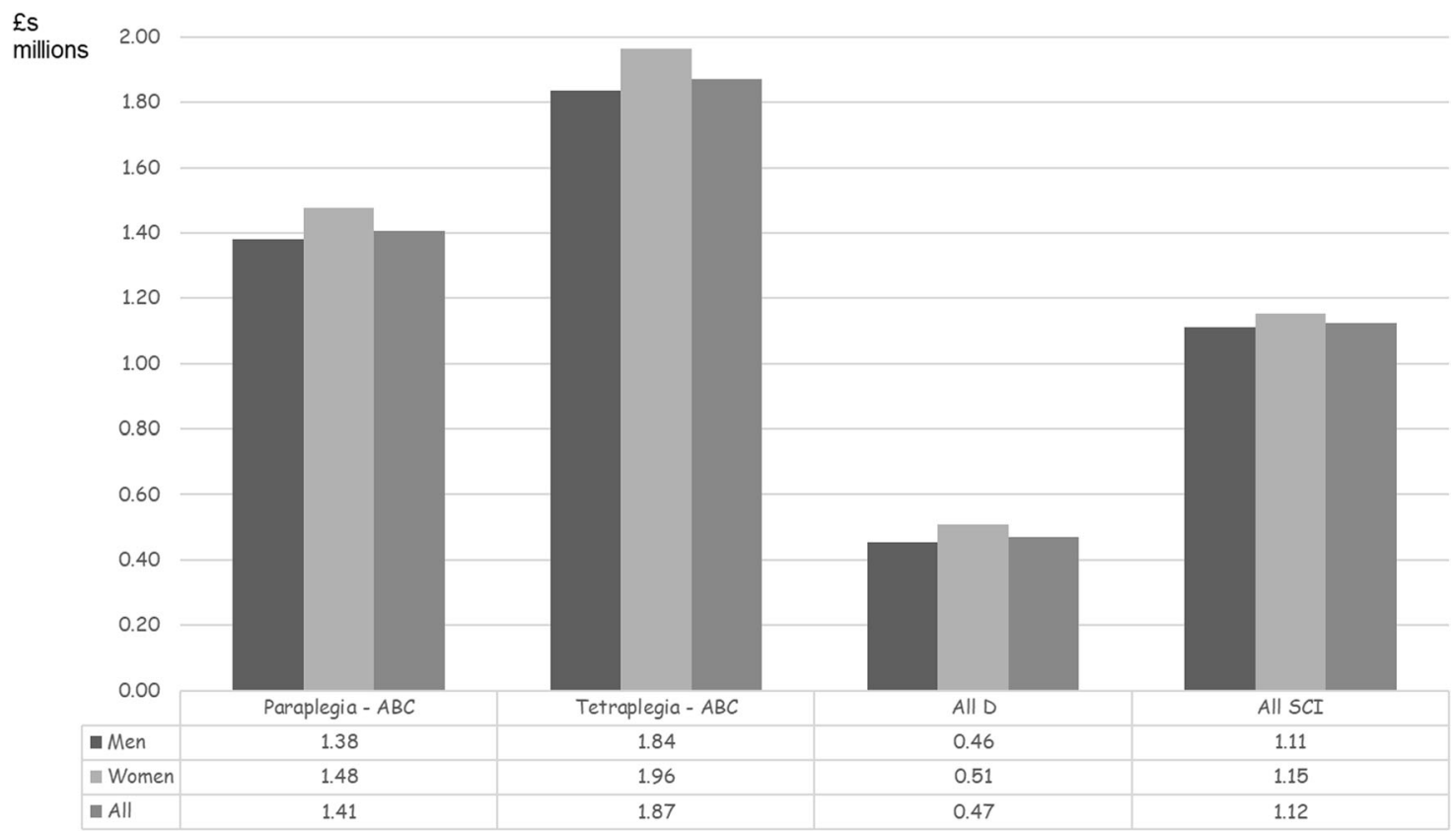

Fig. 2 Mean lifetime costs of new spinal cord injuries by type and gender (2016 $£$ millions) 
Fig. 3 Mean lifetime costs per new tetraplegic traumatic spinal cord injury by age-group and gender (2016 £ millions)

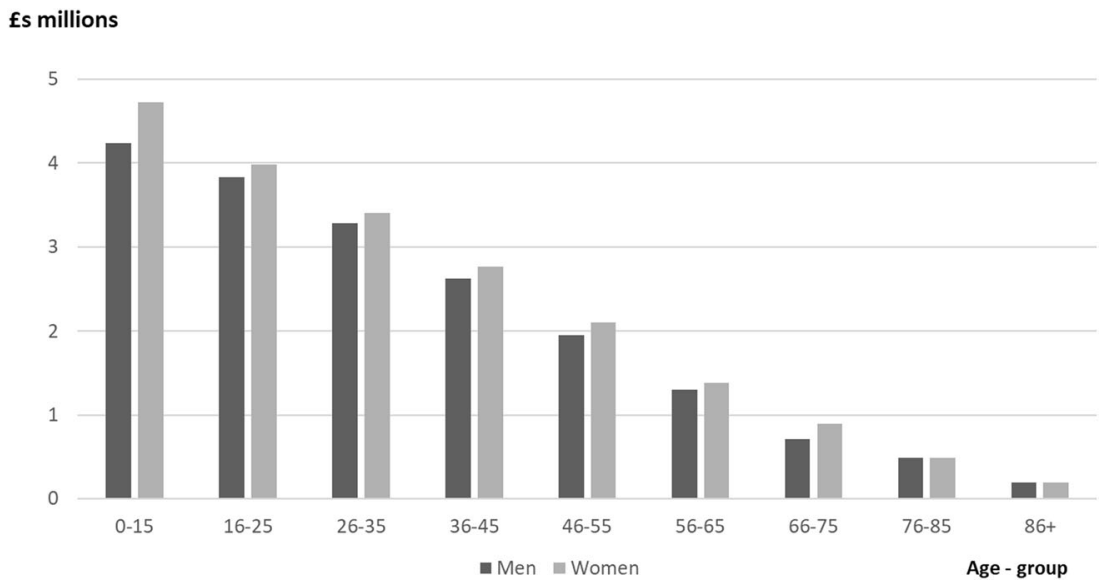

for individuals aged up to 64 and aged $\geq 65$ years, respectively [35]. Costs in the Australian analysis varied dramatically depending on type of injury with mean total hospital costs for sub-groups of individuals ranging from $£ 5353$ for mild-to-moderate injuries for the younger cohort compared with $£ 19,956$ for serious injuries for the older cohort. In Canadian analyses, mean initial year hospital costs for traumatic SCI cases covering health, rehabilitation and continuing care were $£ 72,496$ [9] and $£ 75,192$ [36]. Costs for complete SCI of $£ 92,283$ and $£ 31,950$ for incomplete SCI were also reported [37]. In Spain, first year costs of SCI due to motor vehicle trauma (MVT) or all other causes were modelled [38]. Average healthcare costs, adaptations and specialist ongoing care for the MVT and non-MVT groups were $£ 31,092$ and $£ 30,593$, respectively.

We conclude that, despite the magnitude of costs, this first analysis of UK SCI costs is conservative. Further analyses of UK costs, making use of registry data on longterm resource use, are needed. This would allow analysis to account for SCIs converting from one ASIA grade to another [39]. Work is also needed worldwide to better understand non-traumatic SCI costs. Our model could be adapted and further developed as these data become available.

Our analysis shows how models play a powerful role in highlighting economic impacts of SCI to policymakers and illustrating how changes in patterns of cause, type, age at injury and mortality risk influence future costs. This is important given trends towards higher age at injury, for instance linked to falls rather than traffic accidents. In our model, age at injury substantially impacts on costs, for instance with mean lifetime cost of traumatic tetraplegia in a man aged 36-45 years being $£ 2.63$ million compared with $£ 1.30$ million if aged between 56 and 65 years (Fig. 3), but as Table 4 illustrates $49 \%$ of aggregate costs for the first year of treatment are incurred by those aged $>56$ years. Models are vital tools in bringing together estimates of SCI costs with evidence on effective ways of improving outcomes at individual and population level. They help provide evidence on key policy concerns to be addressed, including the economic case for improved care pathways, prompt referral to specialist SCI centres and reductions in delayed discharges following rehabilitation. Our model also implies a case for evaluating the long-term cost-effectiveness of rehabilitation programmes. If effective in improving compensatory skills and helping SCI patients to use devices that maximise functional performance, then substantive lifetime costs to the public purse and families may be averted.

\section{Data archiving}

The Excel model used to estimate these costs is available on request from the corresponding author. It is also available to download from https://www.spinal-research.org/cost-spina 1-cord-injury.

Acknowledgements The authors would like to thank Fiona Barr, Stuart Coalwood, Claire Guy, Timea Konya and Alan Moodie for their advice and support.

Funding The study was supported by an unrestricted grant from the International Spinal Research Trust.

Author contributions DMD and ALP were responsible for developing the economic model. DMD drafted the paper and all authors read, commented on and provided further input on both the manuscript and model assumptions. All authors approved the final version of the manuscript.

\section{Compliance with ethical standards}

Conflict of interest None of the authors have any direct conflicts of interests, but the analysis presented has been funded through an unrestricted grant to the London School of Economics and Political Science from the International Spinal Research Trust (ISRT). MB is Director of Research at Spinal Research, the UK affiliate of the ISRT. 
Publisher's note: Springer Nature remains neutral with regard to jurisdictional claims in published maps and institutional affiliations.

Open Access This article is licensed under a Creative Commons Attribution 4.0 International License, which permits use, sharing, adaptation, distribution and reproduction in any medium or format, as long as you give appropriate credit to the original author(s) and the source, provide a link to the Creative Commons license, and indicate if changes were made. The images or other third party material in this article are included in the article's Creative Commons license, unless indicated otherwise in a credit line to the material. If material is not included in the article's Creative Commons license and your intended use is not permitted by statutory regulation or exceeds the permitted use, you will need to obtain permission directly from the copyright holder. To view a copy of this license, visit http://creativecommons. org/licenses/by/4.0/.

\section{References}

1. McCaughey EJ, Purcell M, McLean AN, Fraser MH, Bewick A, Borotkanics RJ, et al. Changing demographics of spinal cord injury over a 20-year pgeriod: a longitudinal population-based study in Scotland. Spinal Cord. 2016;54:270-6.

2. NICE. Spinal injury: assessment and initial management. Clinical guideline. London: National Institute for Health and Care Excellence; 2015.

3. Sezer N, Akkus S, Ugurlu FG. Chronic complications of spinal cord injury. World J Orthop. 2015;6:24-33.

4. Graupensperger S, Sweet SN, Evans MB. Multimorbidity of overweight and obesity alongside anxiety and depressive disorders in individuals with spinal cord injury. J Spinal Cord Med. 2018:1-9.

5. Green W, Craig J. Identifying the economic value of the Keiro service pathway. York: York Health Economics Consortium, University of York; 2015.

6. WHO. WHO guide to identifying the economic consequences of disease and injury. Geneva: World Health Organization; 2009.

7. Access Economics. The economic cost of spinal cord injury and traumatic brain injury in Australia. Canberra: Access Economics; 2009.

8. Krueger H, Noonan VK, Trenaman LM, Joshi P, Rivers CS. The economic burden of traumatic spinal cord injury in Canada. Chronic Dis Inj Can. 2013;33:113-22.

9. Chan BC, Cadarette SM, Wodchis WP, Krahn MD, Mittmann N. The lifetime cost of spinal cord injury in Ontario, Canada: A population-based study from the perspective of the public health care payer. J Spinal Cord Med. 2019;42:184-93.

10. Cao Y, Chen Y, DeVivo MJ. Lifetime direct costs after spinal cord injury. Top Spinal Cord Inj Rehabil. 2011;16:10-6.

11. Dukes EM, Kirshblum S, Aimetti AA, Qin SS, Bornheimer RK, Oster G. Relationship of American Spinal Injury Association Impairment Scale grade to post-injury hospitalization and costs in thoracic spinal cord injury. Neurosurgery. 2017;83:445-51.

12. Vervoordeldonk JJ, Post MW, New P, Clin Epi M, Van Asbeck FW. Rehabilitation of patients with nontraumatic spinal cord injury in the Netherlands: etiology, length of stay, and functional outcome. Top Spinal Cord Inj Rehabil. 2013;19: 195-201.

13. Chamberlain JD, Meier S, Mader L, von Groote PM, Brinkhof MW. Mortality and longevity after a spinal cord injury: systematic review and meta-analysis. Neuroepidemiology. 2015;44:182-98.

14. Middleton JW, Dayton A, Walsh J, Rutkowski SB, Leong G, Duong S. Life expectancy after spinal cord injury: a 50-year study. Spinal Cord. 2012;50:803-11.
15. Savic G, DeVivo MJ, Frankel HL, Jamous MA, Soni BM, Charlifue S. Long-term survival after traumatic spinal cord injury: a 70-year British study. Spinal Cord. 2017;55:651-8.

16. NHS England. Reference cost collection: National Schedule of Reference Costs - Year 2015-16 - NHS trust and NHS foundation trusts. London: NHS England; 2016.

17. Laursen B, Helweg-Larsen K. Health service use in adults 20-64 years with traumatic brain injury, spinal cord injury or pelvic fracture. A cohort study with 9-year follow-up. BMJ Open. 2012;2:e001521.

18. Dryden DM, Saunders LD, Rowe BH, May LA, Yiannakoulias N, Svenson LW, et al. Utilization of health services following spinal cord injury: a 6-year follow-up study. Spinal Cord. 2004;42:513-25.

19. DeJong G, Tian W, Hsieh CH, Junn C, Karam C, Ballard PH, et al. Rehospitalization in the first year of traumatic spinal cord injury after discharge from medical rehabilitation. Arch Phys Med Rehabil. 2013;94(4 Suppl):S87-97.

20. Hertig-Godeschalk A, Gemperli A, Arnet U, Hinrichs T. Availability and need of home adaptations for personal mobility among individuals with spinal cord injury. J Spinal Cord Med. 2018;41:91-101.

21. Smith B, Caddick N. The impact of living in a care home on the health and wellbeing of spinal cord injured people. Int J Environ Res Public Health. 2015;12:4185-202.

22. Spinal Injuries Association. Preserving and developing the National Spinal Cord Injury Service. Milton Keynes: Spinal Injuries Association; 2009.

23. British Society of Rehabilitation Medicine. Specialist nursing home care for people with complex neurological disability: guidance to best practice published. London: BSRM; 2013.

24. Khare J. Rehabilitation and reintegration outcomes following spinal cord injury in the UK. London: Brunel University; 2014.

25. Robinson-Whelen S, Rintala DH. Informal care providers for veterans with SCI: who are they and how are they doing? J Rehabil Res Dev. 2003;40:511-6.

26. Curtis L, Burns A. Unit costs of health and social care 2016. Canterbury: PSSRU, University of Kent; 2016.

27. GOV.UK. National minimum wage and national living wage rates. London: GOV.UK; 2018.

28. Savic G, Bergstrom E, Gardner B, Ash D, Hasler J, Tasiemski T. Employment following spinal cord injury - a British multicentre study. 4th ISCoS and ASIA Joint Scientific Meeting; May 14-16; Montreal; 2015.

29. Tomlinson J. Employment: disability: written question - 1718. 17 June 2015. http://www.parliament.uk/business/publications/w ritten-questions-answers-statements/written-question/Commons/ 2015-06-09/1718/. Hansard; 2015.

30. Ames H, Wilson C, Barnett SD, Njoh E, Ottomanelli L. Does functional motor incomplete (AIS-D) spinal cord injury confer unanticipated challenges? Rehabil Psychol. 2017;62:401-6.

31. Schouten R, Keynan O, Lee RS, Street JT, Boyd MC, Paquette SJ, et al. Health-related quality-of-life outcomes after thoracic (T1T10) fractures. Spine J. 2014;14:1635-42.

32. Office for National Statistics. All data related to Annual Survey of Hours and Earnings: 2017 provisional and 2016 revised results. London: ONS; 2017

33. Quesnel A, Veber B, Proust F, Agasse E, Beuret Blanquart F, Verin E. What are the perspectives for ventilated tetraplegics? A French retrospective study of 108 patients with cervical spinal cord injury. Ann Phys Rehabil Med. 2015;58:74-7.

34. Rose L. A paralysed system? An inquiry into the provision of local health services for people being discharged from spinal cord injury centres. London: All Party Parliamentary Group on Spinal Cord Injury; 2015.

35. Mitchell R, Harvey L, Stanford R, Close J. Health outcomes and costs of acute traumatic spinal injury in New South Wales, Australia. Spine J. 2018;18:1172-9. 
36. Munce SE, Wodchis WP, Guilcher SJ, Couris CM, Verrier M, Fung K, et al. Direct costs of adult traumatic spinal cord injury in Ontario. Spinal Cord. 2013;51:64-9.

37. Dryden DM, Saunders LD, Jacobs P, Schopflocher DP, Rowe BH, May LA, et al. Direct health care costs after traumatic spinal cord injury. J Trauma. 2005;59:464-7.
38. Garcia-Altes A, Perez K, Novoa A, Suelves JM, Bernabeu M, Vidal J, et al. Spinal cord injury and traumatic brain injury: a costof-illness study. Neuroepidemiology . 2012;39:103-8.

39. Spiess MR, Muller RM, Rupp R, Schuld C, Group E-SS, van Hedel HJ. Conversion in ASIA impairment scale during the first year after traumatic spinal cord injury. J Neurotrauma. 2009;26:2027-36. 